\title{
Enhancement of antitumor immunity by combination of anti-CTLA-4 antibody and radioimmunotherapy through the suppression of Tregs
}

\author{
CHEOL-HUN SON $^{1 *}$, JAEHO BAE ${ }^{2,3^{*}}$, HONG-RAE LEE ${ }^{1,2}$, KWANGMO YANG $^{1}$ and YOU-SOO PARK ${ }^{1}$ \\ ${ }^{1}$ Department of Research Center, Dongnam Institute of Radiological and Medical Sciences, Busan 619-953; \\ ${ }^{2}$ Department of Biochemistry; ${ }^{3}$ PNU BK21 Plus Biomedical Science Education Center, \\ Pusan National University School of Medicine, Yangsan, Gyeongsangnam-do 626-870, Republic of Korea
}

Received May 9, 2016; Accepted November 10, 2017

DOI: $10.3892 / \mathrm{ol} .2017 .5933$

\begin{abstract}
Cytotoxic T lymphocyte antigen-4 (CTLA-4) is expressed during cluster of differentiation (CD) $4^{+} \mathrm{T}$-cell activation and terminates immune responses by interrupting CD28-enhanced activation. In addition, CTLA-4 is known to be constitutively expressed in regulatory T-cells (Tregs) and to contribute to immune suppression by enhancing the suppressive function of Tregs. However, the molecular mechanisms underlying CTLA-4-mediated Treg suppression remains incompletely understood. Furthermore, it is uncertain whether the in vivo immune suppressive functions of CTLA-4 are mediated only by a reduction in the level of conventional T-cell activity, or enhancement of Treg function. The present study demonstrated that combination therapy with an anti-CTLA-4 monoclonal antibody and dendritic cell-mediated radioimmunotherapy (IR/DC) was able to promote an antitumor response and influence Treg function in a mouse model of lung cancer. Cell surface markers, including CTLA-4, CD25 and CD4, were analyzed using flow cytometry, and T-cell activities were measured using ELISPOT and cytotoxicity assays. It was revealed that anti-CTLA-4 combined treatment with IR/DC immunotherapy may execute a more powerful and effective anti-tumor immunity through the inhibition of Treg function.
\end{abstract}

Correspondence to: Dr You-Soo Park, Department of Research Center, Dongnam Institute of Radiological and Medical Sciences, 40 Jwadong-gil, Gijang-gun, Busan 619-953, Republic of Korea E-mail: biotek01@hanmail.net

${ }^{*}$ Contributed equally

Key words: CTLA-4, radioimmunotherapy, regulatory $\mathrm{T}$ cells, Lewis lung carcinoma

\section{Introduction}

In previous studies, the anti-cytotoxic $\mathrm{T}$ lymphocyte antigen (CTLA)-4 antibody was able to enhance the activity of conventional T-cells through the blockade of CTLA-4, which competes with the costimulatory molecule cluster of differentiation (CD) 28 to bind to the ligands CD80 and CD86 on dendritic cells (DCs) $(1,2)$. However, the mechanism by which CTLA-4 influences the suppressive effect of regulatory T-cells (Tregs) in vivo remains unclear. Although studies have reported that transgenic CTLA-4 enhanced Treg function and anti-CTLA-4 antibodies induced autoimmune colitis through the suppression of Tregs in a mouse model, the presence of anti-CTLA4 antibodies did not affect the suppressive effect of Treg on CD4 ${ }^{+} \mathrm{CD} 25^{-} \mathrm{T}$-cells in mouse gastritis $(3,4)$. Therefore, investigation into the role of CTLA-4 in cancer immunotherapy is required. The present study assessed the inhibition of CTLA-4 using an anti-CTLA-4 monoclonal antibody $(\mathrm{mAb})$, in order to determine whether this inhibition was able to increase the level of antitumor immunity induced by dendritic cell-mediated radioimmunotherapy (IR/DC) in a mouse model in vivo. Since malignant cells may exhibit acquired tolerance to tumor-specific antigens and Tregs may be involved in the survival of tumor cells through the suppression of antitumor immunity $(5,6)$, the present study hypothesized that blocking CTLA-4 may break the tolerance and induce antitumor immunity through the inhibition of Tregs.

\section{Materials and methods}

Mice and cancer cell lines. A total of seventy-five male C57BL/6 mice aged 6 weeks and weighing 18-22 g were purchased from Central Lab., Animal Inc. (Seoul, Korea) and the animal experiments were approved by the Dongnam Institute of Radiological and Medical Sciences Institutional Animal Care and Use Committee (Busan, Korea). All mice were maintained in a specific pathogen-free state under a strict light cycle (lights on at $08: 00 \mathrm{~h}$ and off at $20: 00 \mathrm{~h}$ ) at $21 \pm 2^{\circ} \mathrm{C}$ and $45 \pm 10 \%$ relative humidity. The Lewis lung carcinoma (LLC) CRL-1642 cells, derived from C57BL/6 mice, were obtained from American 
Type Culture Collection (Manassas, VA, USA). The cells were cultured for 7-10 days in Dulbecco's modified Eagle's medium (Invitrogen; Thermo Fisher Scientific, Inc., Waltham, MA, USA) supplemented with $10 \%$ fetal bovine serum (FBS; Biowest, Miami, FL, USA), $100 \mathrm{U} / \mathrm{ml}$ penicillin and $100 \mu \mathrm{g} / \mathrm{ml}$ streptomycin at $37^{\circ} \mathrm{C}$ in a humidified atmosphere containing $5 \% \mathrm{CO}_{2}$.

Isolation of bone marrow-derived DCs. The C57BL/6 mice $(\mathrm{n}=5)$ were sacrificed using $\mathrm{CO}_{2}$ gas and bone marrow cells were isolated from the tibias and femurs. Red blood cells (RBCs) were lysed by treatment with ammonium-chloride-potassium (ACK) lysing buffer (Gibco; Thermo Fisher Scientific, Inc.) and washed with PBS. The $1 \times 10^{6}$ cells $/ \mathrm{ml}$ cells were cultured in $100-\mathrm{mm}$ culture dishes filled with $10 \mathrm{ml}$ RPMI-1640 medium supplemented with 10\% FBS, $50 \mathrm{mM}$ 2-mercaptoethanol (Sigma-Aldrich; Merck Millipore, Darmstadt, Germany), $100 \mathrm{U} / \mathrm{ml}$ penicillin, $100 \mu \mathrm{g} / \mathrm{ml}$ streptomycin, $20 \mathrm{ng} / \mathrm{ml}$ recombinant mouse granulocyte macrophage colony-stimulating factor (R\&D Systems, Inc., Minneapolis, $\mathrm{MN}$, USA) and $10 \mathrm{ng} / \mathrm{ml}$ recombinant mouse interleukin-4 (R\&D Systems, Inc.) for 3 days. Half of the medium was replaced with fresh medium every day. On the 6th day, the non-adherent cells were collected by pipetting and the surface markers on the cells, such as CD80 $(0.2 \mathrm{mg} / \mathrm{ml}$; cat. no., 553769 ; BD Pharmingen, San Diego, CA, USA), CD86 (0.2 mg/ml; cat. no., 553692; BD Pharmingen), I-A-I-E $(0.2 \mathrm{mg} / \mathrm{ml}$; cat. no., 557000; BD Pharmingen), CD11c $(0.5 \mathrm{mg} / \mathrm{ml}$; cat. no., 553801; BD Pharmingen) were analyzed using a FC500 flow cytometer (Beckman Coulter, Inc., Miami, FL, USA).

Ionizing radiation (IR) and immunization procedure. The IR and immunization procedures are shown in Fig. 1. Briefly, LLC cells were transplanted subcutaneously into the right thigh $\left(3 \times 10^{5}\right.$ cells $)$ and left flank $\left(1.5 \times 10^{5}\right.$ cells $)$ of the mice (12 mice/group). When the diameter of tumor masses reached $\sim 10 \mathrm{~mm}$, IR was applied at a dose of $12 \mathrm{~Gy}$ (6 MV photon beam, dose rate of $6.1 \mathrm{~Gy} / \mathrm{min}$ ) to the tumors on the right thighs of the mice using a linear accelerator (Infinity; Elekta Limited, Crawley, UK). Dosimetry was evaluated using an ionization chamber connected to an electrometer system, according to the International Atomic Energy Agency (IAEA) guideline (IAEA TRS-398) (7). Prior to irradiation, the mice were anesthetized with an intraperitoneal injection of $50 \mathrm{mg}$ zoletile (Virbac, Nice, France) plus $5 \mathrm{mg}$ rompun (Bayer Korea, Ansan, Korea) per kg body weight and placed in a customized restraining device and positioned. The irradiation field square was set as $20 \times 20 \mathrm{~cm}$ and the radiation was focused on the legs of the mice to minimize whole body exposure. After $24 \mathrm{~h}, 1 \times 10^{6}$ cells $/ 100 \mu 1$ immature DCs were injected into the irradiated tumor for immunization. Immunization was performed 3 times at 1-week intervals. Tumor size was measured twice per week using the following formula: Tumor size $\left(\mathrm{mm}^{2}\right)=$ length $(\mathrm{mm}) \mathrm{x}$ width $(\mathrm{mm})$. The $100 \mu \mathrm{l}$ anti-CTLA-4 mAb (diluted to $2 \mathrm{mg} / \mathrm{ml}$ with PBS; catalog no., BE0103; clone 9H10; Bio X Cell, West Lebanon, $\mathrm{NH}$, USA) was administered intraperitoneally to the mice on the same day as every iDC injection.

Flow cytometric analysis. The proportion and number of effector T-cells and $\mathrm{CD} 4{ }^{+} \mathrm{CD} 25^{+}$forkhead box P3 (FOXP3) ${ }^{+}$cells within the total $\mathrm{CD} 4^{+}$cell population was evaluated following IR/iDC combined with anti-CTLA- 4 mAb treatment. The C57BL/6 mice (5 mice/group) were sacrificed using $\mathrm{CO}_{2}$ gas to harvest their tumor tissue and spleens, after 4 days following the final immunization. Tumor infiltrating leukocytes $\left(1 \times 10^{5}\right.$ cells $\left./ \mathrm{ml}\right)$ were prepared from individual tumor tissues cut with scissors and dissociated using $0.04 \mathrm{mg} / \mathrm{ml}$ Liberase (Roche Applied Science, Penzberg, Germany) in RPMI-1640 medium (Welgene, Daegu, Korea) at $37^{\circ} \mathrm{C}$ for $90 \mathrm{~min}$, followed by passage through a $0.45-\mu \mathrm{m}$ nylon mesh (BD Pharmingen). Single cell suspensions of splenocytes $\left(1 \times 10^{7}\right.$ cells $\left./ \mathrm{ml}\right)$ were obtained by grinding the spleens, followed by passage through a $0.45-\mu \mathrm{m}$ nylon mesh. RBCs were lysed using $1 \mathrm{X}$ ACK lysing buffer at room temperature for $2 \mathrm{~min}$. The separated cells were washed with PBS and immunostained with phycoerythrin (PE)-conjugated anti-mouse CD4 (BD Pharmingen, catalog no., 553652) and PE-cyanin7 (Cy7)-conjugated anti-mouse CD25 (BD Pharmingen, catalog no., 552880), respectively, at a concentration of $20 \mu \mathrm{l} / 10^{6}$ cells, in the dark at $4^{\circ} \mathrm{C}$ for $30 \mathrm{~min}$. The $\mathrm{CD} 4 / \mathrm{CD} 25$ double stained cells were resuspended in a 1:4 dilution (total volume $1 \mathrm{ml}$ ) of TF Fix/Perm Buffer (transcription factor buffer set; BD Pharmingen; catalog no., 562725) and incubated at $4^{\circ} \mathrm{C}$ for $40 \mathrm{~min}$ in the dark. The permeabilized cells were stained with PE-Cy5-conjugated anti-mouse FOXP3 (eBioscience, CA, USA; catalog no., 15-5773-82) at a concentration of $20 \mu 1 / 10^{6}$ cells and were incubated at $4^{\circ} \mathrm{C}$ for $30 \mathrm{~min}$ in the dark. Subsequently, the cells were washed in a 1:5 dilution (total volume $2 \mathrm{ml}$ ) of TF Perm/Wash Buffer (transcription factor buffer set; BD Pharmingen; catalog no., 562725). Flow cytometry analysis was performed on a FC500 flow cytometer. Results were generated using CXP v1.0 Software (Beckman Coulter, Inc.).

Enzyme-linked immunospot (ELISpot) assay. ImmunoSpot plates for ELISpot (Merck Millipore) were pretreated with $35 \%$ ethanol for $1 \mathrm{~min}$ at room temperature. Following the removal of the ethanol, the plates were coated with capture antibodies (10 $\mu \mathrm{g} / \mathrm{ml}$; cat. no., 51-1818KA; BD Pharmingen) overnight at $4^{\circ} \mathrm{C}$. The plates were blocked with $10 \mathrm{~g} / 1$ bovine serum albumin (Sigma-Aldrich; Merck Millipore) for $2 \mathrm{~h}$ and washed three times with PBS. Splenocytes $\left(0.5 \times 10^{6}\right.$ cells/well $)$ and $50 \mu \mathrm{g} / \mathrm{ml}$ LLC cell lysates were added to each well and incubated at $37^{\circ} \mathrm{C}$ for $24 \mathrm{~h}$. The plate was washed three times with PBS and an additional three times with PBS-Tween buffer, and biotinylated detection antibodies (diluted to $2 \mu \mathrm{g} / \mathrm{ml}$ with PBS; catalog no., 51-1818KA; BD Pharmingen) were added and the plate was incubated for $2 \mathrm{~h}$ at room temperature. The plates were washed $>3$ times with PBS-Tween buffer. Streptavidin-horseradish peroxidase (100 $\mu 1$ per well) was then added, and the plates were incubated for $2 \mathrm{~h}$ at room temperature. Subsequent to being washed twice with PBS, a chromogenic substrate and $\mathrm{H}_{2} \mathrm{O}_{2}$ (AEC substrate; catalog no., 551951; BD Pharmingen) were added to each well to produce visible spots. When adequate spots were developed, distilled water was added to stop the reaction and the plates were air-dried overnight. The number of spots were calculated and the images were analyzed using an EliSpot Reader System (Autoimmun Diagnostika GmbH, Strassberg, Germany).

Cytotoxicity assay. Splenoctyes $\left(3 \times 10^{7}\right)$ isolated from the mice of each group were stimulated by co-culture with 

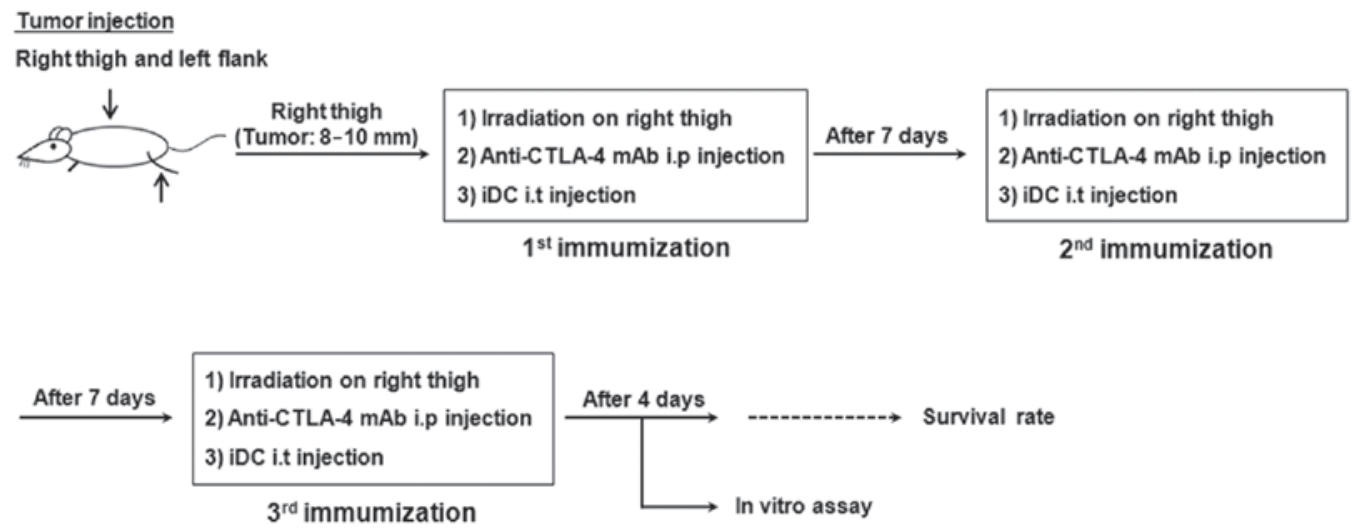

Figure 1. Schematic of the schedule for combination treatment with the anti-CTLA-4 mAb and IR/DC. C57BL6 mice (5 mice/group) were subcutaneously injected with Lewis lung carcinoma cells into the right thigh and the right and left flank. When the tumor grew to $\sim 10$ mm, ionizing radiation was applied to the tumor on the right thigh and DCs were injected into the irradiated tumor. IR/DC was performed 3 times at 1-week intervals. The anti-CTLA-4 mAb was administered intraperitoneally to the mice on the same day as every DC injection. IR/DC, dendritic cell-mediated radioimmunotherapy; CTLA-4, cytotoxic T lymphocyte antigen-4; DC, dendritic cells; mAb, monoclonal antibody; i.p., intraperitoneal; i.t., intrathecal; iDC, immature dendritic cell.

mitomycin C (Sigma-Aldrich; Merck Millipore) and $10 \mu \mathrm{g} / \mathrm{ml}$ treated LLC cells ( $3 \times 10^{6}$ cells) for 5 days. The LLC cells were labeled with 5-carboxyfluorescein diacetate succinmidyl ester (CFSE; eBioscience, Inc., San Diego, CA, USA) at a concentration of $5 \mu \mathrm{M}$ for $10 \mathrm{~min}$ at $37^{\circ} \mathrm{C}$ in a humidified incubator with $5 \% \mathrm{CO}_{2}$. Subsequent to labeling, the cells were washed with RPMI-1640 medium containing 10\% FBS. Stimulated splenocytes (effector cells) were co-cultured with CFSE-labeled LLC cells (target cells; 2x104/well) at the appropriate effector-to-target cell count ratios (target cell: effect cell, 40:1; 20:1; 10:1) in round-bottomed plates at $37^{\circ} \mathrm{C}$ in a humidified atmosphere containing $5 \% \mathrm{CO}_{2}$ for $6 \mathrm{~h}$. Subsequent to incubation, the cells were transferred to tubes and placed in an ice water bath. Propidium iodide $(50 \mu \mathrm{g} / \mathrm{ml})$ was added for DNA labeling of dead cells. The dead cells were analyzed using a FC500 flow cytometer. Results were generated using CXP v1.0 Software (Beckman Coulter, Inc, Brea, CA, USA).

Statistical analysis. Statistical analysis was performed using one-way analysis of variance followed by Tukey's multiple comparison test and log-rank tests. $\mathrm{P}<0.05$ was considered to indicate a statistically significant difference. The software used for statistical analysis was SPSS-18 software (SPSS, Inc., Chicago, IL, USA).

\section{Results}

Anti-CTLA-4 mAb enhances the antitumor effect of IR/DC in a mouse model of lung cancer. To evaluate the systemic antitumor effects of anti-CTLA-4 mAb and IR/DC, LLC transplanted mice were treated with single agents or the combination therapy 3 times at 1-week intervals. The growth of distant tumors was significantly suppressed by treatment with IR/DC and combined therapy (Fig. 2A). Single treatment with IR or anti-CTLA-4 mAb did not significantly inhibit distant tumor growth. Similar results were shown in the survival test; combination therapy significantly increased the survival of the mice (Fig. 2B). Although single treatment with anti-CTLA-4 mAb exhibited only a small effect when used alone, this treatment markedly enhanced the antitumor effect of IR/DC in terms of the tumor growth rate and survival time (Fig. 2). These results suggest that, although the anti-CTLA-4 mAb may be ineffective with respect to inducing antitumor immunity, it may be a good enhancer of immune reponse in other types of immunotherapy.

Ratio of Tregs to $C D 4^{+} T$-cells was decreased in the spleen and tumors following combined therapy. Since it was thought that the function of Tregs was affected by treatment with an anti-CTLA-4 mAb and IR/DC, the ratios of Tregs to CD4 ${ }^{+}$ T-cells in the spleens (Fig. 3A) and tumors (Fig. 3B) were measured. In the present study, $\mathrm{CD}^{+} \mathrm{T}$-cells and Tregs were detected using fluorescence-conjugated anti-CD4, anti-CD25 and anti-FOXP3 mAbs (Fig. 3C). The ratios of Tregs to CD4 ${ }^{+}$ T-cells were significantly decreased by treatment with IR/DC. Although single treatment with the anti-CTLA-4 mAb did not affect the proportion of Tregs, the Treg proportion was reduced by combination treatment with the anti-CTLA- 4 mAb and IR/DC. Decreased ratio of Treg could derived from the decreased number of Treg cells and decreased proliferation of conventional T-cells. Although the decreased ratio of Tregs to $\mathrm{CD}^{+}{ }^{+} \mathrm{T}$-cells did not distinguish a reduced number of Tregs from the proliferation of conventional $\mathrm{CD} 4^{+} \mathrm{T}$-cells, it was certain that decreased ratio of Treg contributed to the induction of antitumor immunity.

Combined therapy decreases the number of Tregs and increases the number of conventional T-cells in the mouse spleen. Following dissection and weighing, the spleens were mashed and the total splenocytes were counted. The number of Tregs per g/spleen was calculated, and the number was significantly decreased following treatment with IR/DC and combined therapy compared to untreated control (Fig. 3D). Single treatment with the anti-CTLA-4 mAb did not significantly alter the number of Tregs. To evaluate the influence of IR/DCand the anti-CTLA-4 mAb on two types of T-cells, total numbers of conventional $\mathrm{CD} 4^{+} / \mathrm{CD} 25^{-}$and $\mathrm{CD} 8^{+} \mathrm{T}$-cells were also calculated. The numbers of $\mathrm{CD}^{+} / \mathrm{CD} 25^{-}$and $\mathrm{CD} 8^{+} \mathrm{T}$-cells were significantly increased in the mice following treatment with IR/DC, and the numbers of cells were further increased 
A

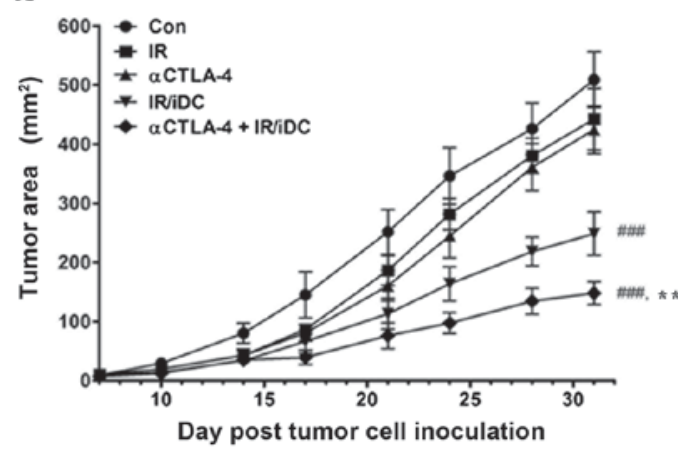

B

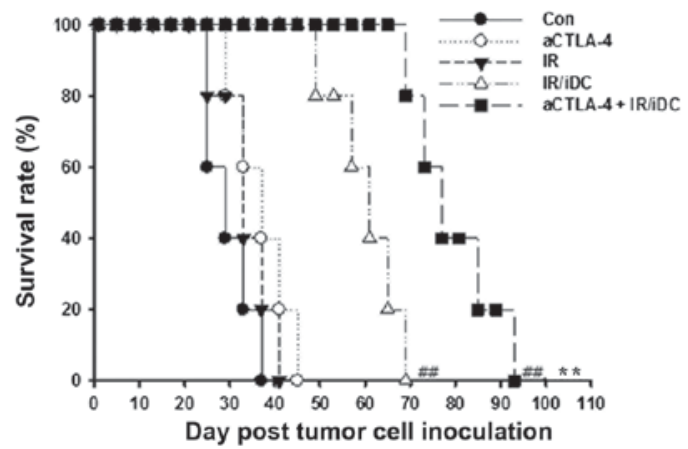

Figure 2. Antitumor effect of anti-CTLA-4 and IR/DC treatment, based on three independent experiments. (A) Tumor size on left flank was measured using a caliper twice per week. (B) Survival rates of the mice are presented as Kaplan-Meier survival curves from an experiment using 5 mice per group. ${ }^{\# /} \mathrm{P}<0.005$,

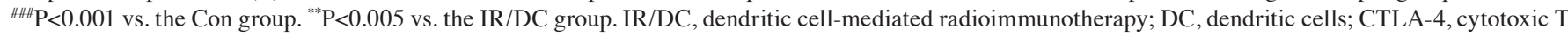
lymphocyte antigen-4; Con, control; IR, ionizing radiation.
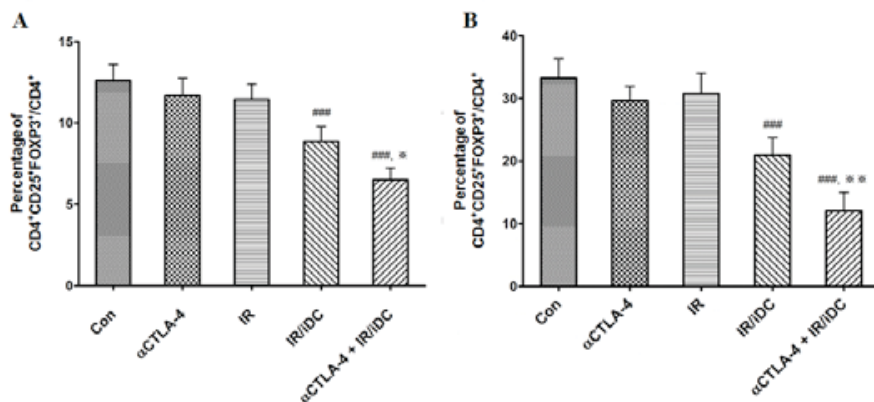

E

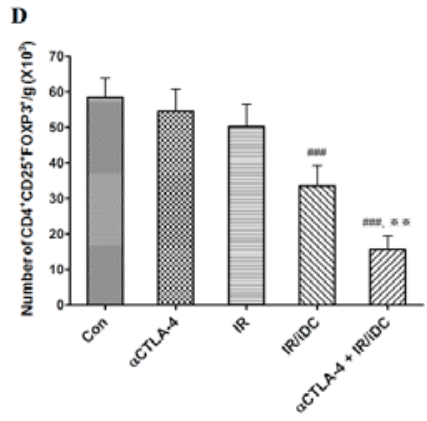

C
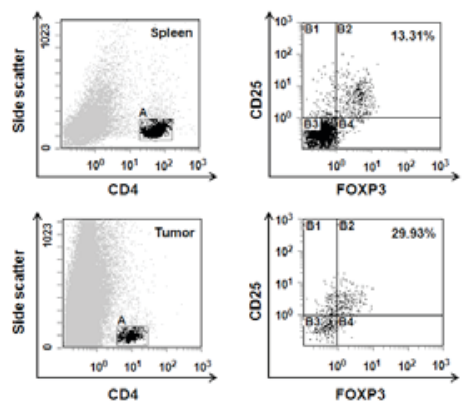

$\mathbf{F}$
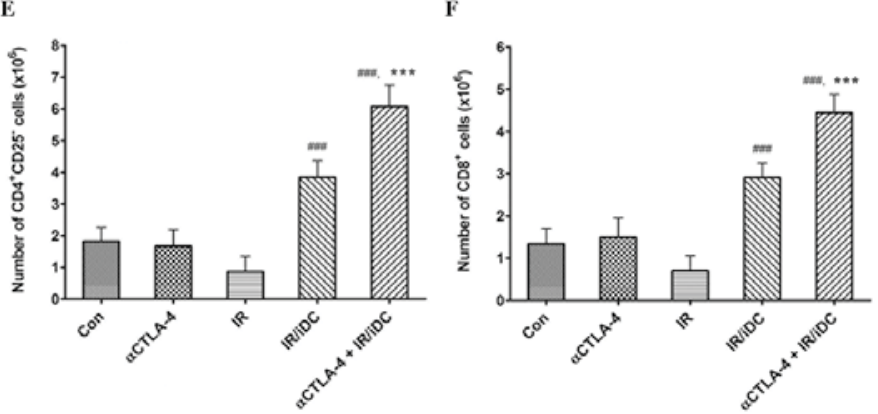

Figure 3. Proportion of Tregs to CD4 ${ }^{+} \mathrm{T}$-cells, and the number of Tregs and conventional T-cells in the spleens and tumors of a mouse model of lung disease. Ratios of Tregs to $\mathrm{CD}^{+}{ }^{+} \mathrm{T}$-cells in the (A) spleens and (B) tumors were measured. (C) The percentages of $\mathrm{CD} 4^{+} \mathrm{T}$-cells and Tregs were detected by flow cytometric analysis. (D) The number of Tregs per grams of spleen was calculated following the various treatments. The numbers of (E) $\mathrm{CD}^{+} / \mathrm{CD}^{-} 5^{\circ}$ and (F) $\mathrm{CD}^{+}$ T-cells were assayed following the various treatments. ${ }^{\# \# \# P} \mathrm{P}<0.001$ vs. the Con group. ${ }^{*} \mathrm{P}<0.05,{ }^{* * *} \mathrm{P}<0.005$ and ${ }^{* * * *} \mathrm{P}<0.001$ vs. the IR/DC group. IR/DC, dendritic cell-mediated radioimmunotherapy; CTLA-4, cytotoxic T lymphocyte antigen-4; CD, cluster of differentiation; Con, control; IR, ionizing radiation; FOXP3, forkhead box P3; iDC, immature dendritic cell.

by combined therapy with the anti-CTLA-4 mAb and IR/DC (Fig. 3E and F).

Number of tumor-specific T cells is increased following treatment with the anti-CTLA-4 $\mathrm{mAb}$ and/or IR/DC, but not subsequent to IR. Since the ratio of reactive T-cells to tumor antigen is small, it is important the absolute quantity of T-cells respond to specific tumor antigens and secrete the tumor protective cytokine, IFN- $\gamma$. When tumor antigens reactive T-cells were counted using an EliSpot assay, the number of IFN- $\gamma$ spots secreted by activated T-cells was significantly increased following treatment with the anti-CTLA-4 mAb alone, IR/DC alone and the combined therapy (Fig. 4). This result suggests that the anti-CTLA- $4 \mathrm{mAb}$ and IR/DC enhance antitumor immunity through an increased number of general immune cells and the clonal expansion of specific T-cells against tumor antigens.

Splenocytes activated by combination therapy are more cytotoxic to tumor cells than splenocytes activated by single agent therapy. In the present study, effective immune responses were revealed to be induced by combination therapy with the anti-CTLA-4 mAb and IR/DC, and immunized splenocytes were shown to effectively destroy tumor cells (Fig. 5). The specific lysis of LLC cells was increased by splenocytes activated by IR/DC compared with inactivated splenocytes, and it was further increased when IR/DC was combined with the anti-CTLA-4 mAb. It was previously 


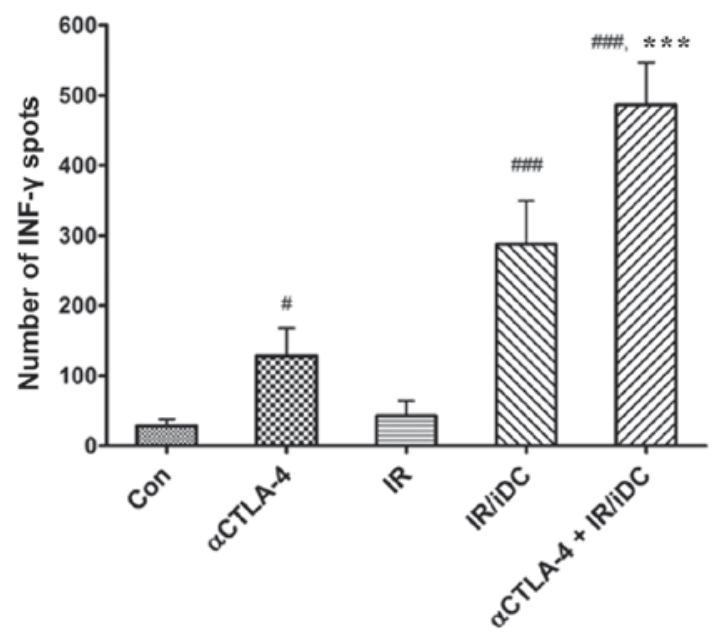

Figure 4. Number of tumor-specific T-cells following treatment with the anti-CTLA-4 antibody and IR/DC. Tumor-specific T-cells were counted using an EliSpot assay and the number of IFN $-\gamma$ spots secreted by activated T-cells was counted following the various treatments. ${ }^{\# P}<0.005$, ${ }^{\# \#} \mathrm{P}<0.0005$ vs. the Con group. ${ }^{* * *} \mathrm{P}<0.0005$ vs. the IR/DC group. IR/DC, dendritic cell-mediated radioimmunotherapy; Con, control; IR, ionizing radiation; CTLA-4, cytotoxic T lymphocyte antigen-4; IFN, interferon.

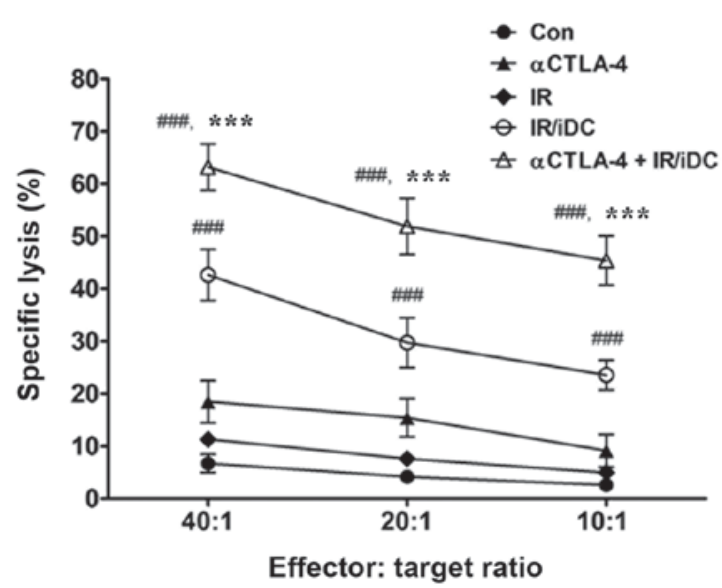

Figure 5. Cytotoxicity of splenocytes on tumor cells following treatment with the anti-CTLA- 4 antibody and IR/DC. The tumor cells were co-cultured with splenocytes isolated from mice subsequent to treatment with the anti-CTLA-4 antibody or IR/DC. The specific lysis of the tumor cells was calculated. All experiments were performed in triplicate. ${ }^{\# \#} \mathrm{P}<0.0005$ vs. the Con group. ${ }^{* * *} \mathrm{P}<0.0005$ vs. the IR/DC group. IR/DC, dendritic cell-mediated radioimmunotherapy; CTLA-4, cytotoxic T lymphocyte antigen-4; iDC, immature dendritic cell; Con, control.

suggested that IR/DC is a potent strategy to induce antitumor immunity $(8,9)$. However, the combination of IR/DC with the anti-CTLA-4 mAb may be a more effective for immunotherapy by overcoming an immune checkpoint, CTLA- 4 .

\section{Discussion}

Tregs serve a central role in the maintenance of immune homeostasis and self-tolerance. However, due to their highly suppressive functions, elevated Treg numbers assist the survival of tumors by promoting evasion of immune surveillance (10) and, therefore, represent a major obstacle to successful immunotherapy (11). Following the discovery of the expression of CTLA-4 on the surface of T-cells, certain functions of CTLA-4 have been hypothesized, including competition with the costimulatory molecule $\mathrm{CD} 28$ on $\mathrm{CD}^{+} / \mathrm{CD} 25^{-} \mathrm{T}$-cells for binding to the CD80 and CD86 ligands on antigen presenting cells (APCs), as well as the direct inhibition of APCs and $\mathrm{CD}^{+} / \mathrm{CD} 25^{-}$T-cells by CTLA-4 and CD80/86 interactions (12). Currently, two types of human anti-CTLA-4 mAbs, ipilimumab and tremelimumab, are being used in the treatment of metastatic melanoma and metastatic mesothelioma $(13,14)$. However, the precise role of CTLA-4 in Tregs during cancer immunotherapy remains unclear. Therefore, an investigation into the role of CTLA-4 on Tregs in cancer immunotherapy was required. The present study revealed that blocking CTLA-4 using an anti-CTLA-4 mAb increased the level of antitumor immunity that was induced by IR/DC, and consequently inhibited tumor growth in vivo. However, single treatment with the anti-CTLA- 4 mAb was not sufficient to evoke antitumor immunity or a reduction in the number of Tregs despite a slight increase in the number of tumor-specific T-cells.

Since malignant cells may evade early immune surveillance and acquire tolerance to tumor-specific antigens, breaking the acquired tolerance and enhancing antitumor immunity is required for successful immunotherapy (15). Immune check point proteins such as CTLA-4 and programmed cell death protein-1 have been suggested to contribute to the evasion of immune surveillance by tumor cells; thus inhibiting these proteins may enhance antitumor immunity $(16,17)$. The competitive influence of CTLA- 4 on conventional T-cells and Tregs have previously been reported $(1,3)$. In addition, an increased number of Tregs has been associated with treatment failure and a poor prognosis of cancer patients. The present study demonstrated that an anti-CTLA-4 mAb inhibited tumor growth in vivo through altered Treg function or proliferation.

Although it is known that anti-CTLA-4 mAbs exhibit antitumor effects on several types of cancer (18-20), the benefit of this treatment alone was limited until now. However, it was found that anti-CTLA-4 combined treatment with IR/DC immunotherapy may provide a more powerful and effective modality to treat patients with cancer through the efficient reduction of Treg function.

\section{Acknowledgements}

The present study was supported by a National Research Foundation of Korea grant funded by the Korean government (grant no. 50595-2015).

\section{References}

1. Birebent B, Lorho R, Lechartier H, de Guibert S, Alizadeh M, Vu N, Beauplet A, Robillard N and Semana G: Suppressive properties of human $\mathrm{CD} 4{ }^{+} \mathrm{CD} 25^{+}$regulatory $\mathrm{T}$ cells are dependent on CTLA-4 expression. Eur J Immunol 34: 3485-3496, 2004.

2. Pedicord VA, Montalvo W, Leiner IM and Allison JP: Single dose of anti-CTLA-4 enhances CD8 ${ }^{+} \mathrm{T}$-cell memory formation, function, and maintenance. Proc Natl Acad Sci USA 108: 266-271, 2011.

3. Takahashi T, Tagami T, Yamazaki S, Uede T, Shimizu J, Sakaguchi N, Mak TW and Sakaguchi S: Immunologic self-tolerance maintained by $\mathrm{CD} 25(+) \mathrm{CD} 4(+)$ regulatory $\mathrm{T}$ cells constitutively expressing cytotoxic T lymphocyte-associated antigen 4. J Exp Med 192: 303-310, 2000.

4. Liu $\mathrm{H}, \mathrm{Hu} \mathrm{B}, \mathrm{Xu} \mathrm{D}$ and Liew FY: $\mathrm{CD} 4{ }^{+} \mathrm{CD} 25^{+}$regulatory T cells cure murine colitis: The role of IL-10, TGF-beta and CTLA4. J Immunol 171: 5012-5017, 2003. 
5. Houghton AN and Guevara-Patino JA: Immune recognition of self in immunity against cancer. J Clin Invest 114: 468-471, 2004.

6. Nishikawa $\mathrm{H}$ and Sakaguchi S: Regulatory $\mathrm{T}$ cells in tumor immunity. Int J Cancer 127: 759-767, 2010.

7. Andreo P, Burns DT, Hohlfeld K, Huq MS, Kanai T, Laitano F, Smyth VG and Vynckier S: Absorbed dose determination in external beam radiotherapy: An international code of practice for dosimetry based on standards of absorbed dose to water. Tech Report Series No. 398. International Atomic Energy Agency, Vienna, pp1-183, 2006.

8. Son CH, Bae JH, Shin DY, Lee HR, Yang K and Park YS: Antitumor effect of dendritic cell loaded ex vivo and in vivo with tumor-associated antigens in lung cancer model. Immunol Invest 43: 447-462, 2014.

9. Kim KW, Kim SH, Shin JG, Kim GS, Son YO, Park SW, Kwon BH, Kim DW, Lee CH, Sol MY, et al: Direct injection of immature dendritic cells into irradiated tumor induces efficient antitumor immunity. Int J Cancer 109: 685-690, 2004.

10. Facciabene A, Motz GT and Coukos G: T-regulatory cells: Key players in tumor immune escape and angiogenesis. Cancer Res 72: 2162-2171, 2012.

11. Voena C and Chiarle R: Advances in cancer immunology and cancer immunotherapy. Discov Med 21: 125-133, 2016.

12. Sansom DM and Walker LS: The role of CD28 and cytotoxic T-lymphocyte antigen-4 (CTLA-4) in regulatory T-cell biology. Immunol Rev 212: 131-148, 2006.

13. Niezgoda A, Niezgoda P and Czajkowski R: Novel approaches to treatment of advanced melanoma: A review on targeted therapy and immunotherapy. BioMed Res Int 2015: 851387, 2015.

14. Calabrò L, Ceresoli GL, di Pietro A, Cutaia O, Morra A, Ibrahim R and Maio M: CTLA4 blockade in mesothelioma: Finally a competing strategy over cytotoxic/target therapy? Cancer Immunol Immunother 64: 105-112, 2015.
15. Staveley-O'Carroll K, Sotomayor E, Montgomery J, Borrello I, Hwang L, Fein S, Pardoll D and Levitsky H: Induction of antigen-specific $\mathrm{T}$ cell anergy: An early event in the course of tumor progression. Proc Natl Acad Sci USA 95: 1178-1183, 1998.

16. van Elsas A, Hurwitz AA and Allison JP: Combination immunotherapy of B16 melanoma using anti-cy totoxic T lymphocyte-associated antigen 4 (CTLA-4) and granulocyte/macrophage colony-stimulating factor (GM-CSF)-producing vaccines induces rejection of subcutaneous and metastatic tumors accompanied by autoimmune depigmentation. J Exp Med 190: 355-366, 1999.

17. Dong H, Strome SE, Salomao DR, Tamura H, Hirano F, Flies DB Roche PC, Lu J, Zhu G, Tamada K, et al: Tumor-associated B7-H1 promotes T-cell apoptosis: A potential mechanism of immune evasion. Nat Med 8: 793-800, 2002.

18. Yang YF, Zou JP, Mu J, Wijesuriya R, Ono S, Walunas T, Bluestone J, Fujiwara H and Hamaoka T: Enhanced induction of antitumor T-cell responses by cytotoxic T lymphocyte-associated molecule-4 blockade: The effect is manifested only at the restricted tumor-bearing stages. Cancer Res 57: 4036-4041, 1997.

19. Paradis TJ, Floyd E, Burkwit J, Cole SH, Brunson B, Elliott E, Gilman S and Gladue RP: The anti-tumor activity of anti-CTLA-4 is mediated through its induction of IFN gamma. Cancer Immunol Immunother 50: 125-133, 2001.

20. Fecci PE, Ochiai H, Mitchell DA, Grossi PM, Sweeney AE, Archer GE, Cummings T, Allison JP, Bigner DD and Sampson JH: Systemic CTLA-4 blockade ameliorates glioma-induced changes to the $\mathrm{CD}^{+} \mathrm{T}$ cell compartment without affecting regulatory T-cell function. Clin Cancer Res 13: 2158-2167, 2007. 